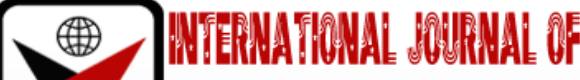

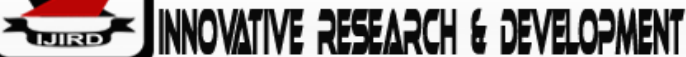

ISSN 2278 - 0211 (Online)

\section{Employee Humility as a Catalyst for Knowledge Sharing Behavior in Kenya's Universities}

\author{
Samwel Kiplagat Maiyo \\ Lecturer, Department of Education, Kisii University, Kenya
}

\begin{abstract}
:
Purpose - This paper is purposed to provide a deeper understanding to the current concept of humility and its role in higher education as far as knowledge dissemination is concerned. Since humility has become increasingly important in latest years, and is recognized as a critical asset for universities particularly due to the growing complexity of dynamic knowledge base environments and the further advancement of regulatory frameworks for competitive advantage. Humility in institutions of higher learning is an idea whose time has come. In light of anticipated challenges and changes that continue to unfold in the 21st century, scholars in public and private universities have suggested a greater need for organizational members to have the humility to acknowledge areas of ignorance and inexperience and to foster the learning and adaptation that will be required to succeed in an increasingly unpredictable workplace.

Design/methodology/approach - Explanatory and confirmatory factor analysis have been conducted to explore and validate the factor of humility as a construct of emotional intelligence. The paper is based on an explanatory study that targeted a population of 6,423 academic staff employees in Kenya from 49 selected universities. A sample size of 378 employees was systematically selected and data collected using a structured questionnaire anchored on a fivepoint Likert scale. The instrument was evaluated for internal consistency and subjected to principal component analysis to explore extant dimensions.

Findings: Though humility awareness by academic staff of universities is widely known, more insights need to be drawn to expound more from the benefit of knowledge sharing behavior's regression results indicated that Humility has a positive and significant effect on knowledge sharing behavior $(\beta=0.30, p<0.05)$. Universities in Kenya should be encouraged to focus on humility in order to improve on knowledge sharing behaviours of academic staff since it was evident that whenever academic staff had greater humility in the university, they would inspire and influence universities competitive advantage through knowledge and emotional intelligence. It is treating all people regardless of who they are, with respect, gentleness, kindness, and forgiveness. A person who is humble shares knowledge without measure of superiority, arrogance, and haughtiness of a person towards other people and understands what drives their behaviour, as well as the effects that it has on others as the most common trademarks of intelligence that value the enhancement of knowledge sharing behavior in modern universities as revealed by the study.

Originality/value - Humility awareness as a catalyst in universities in Kenya have relatively been downplayed by institutions of higher learning, University management and scholars especially in harnessing knowledge.
\end{abstract}

Keywords: Humility, knowledge sharing behaviour, catalyst, universities, and Kenya

\section{Introduction}

Studies on humility have provided little attention to African unique humble university setting situations. Furthermore, academic staff as a unit of analysis in humility studies have received scant attention in the academic literature (. (Grieve et al., 2013). Furthermore, humility is one of the core characteristics of human beings, organizing their life around their relations with other people. Universities humility impacts on the scholar's ability to share knowledge more vividly in order to get to know each other the more they acknowledge each other's' abilities. Each individual comes with his/her unique set of ideas, perspectives and work style. Foss, et al (2010) agreed upon the fact that knowledge sharing through humility among academic staff is highly beneficial to the universities, providing for improved innovation capacity, greater problem-solving capacity, new knowledge, and capabilities, all of these sustaining the competitive advantage of the organization.

Legitimate, Humility is a virtue that concerns human limits on how to view and handle human limits productively, adaptively, and constructively. Given its focus on limits, no wonder humility makes some uncomfortable. Grenberg (2005) and has been identified as a much-neglected topic in social science (Tangney, 2000). Similarly, a great deal of research and popular attention has been devoted to the role of humility in organizations since 2000 . Humility has recently been defined as a dispositional quality of a person whether that person is a leader or an employee that reflects 'a self-view that 
something greater than the self exists'. This exposes humility as an important construct on knowledge sharing behavior. (Ou et al. 2014, p. 37).

Biwott, et al., (2019), drawing from SET theory, posits that possessing empathic traits does not necessarily involve feeling compassion for others, but rather understanding their emotional makeup and treating them according to subsequent reactions. Trademarks consist of customer service skills, the ability to recruit talent, and sensitivity to sociocultural factors`such as gender, ethnicity, or sexual orientation. Bock, et al (2005) says that the sharing of knowledge between individuals, and between them and the organization relies significantly more on staff knowledge sharing behaviors than on institutional context. If the institution is not built around a knowledge-friendly culture from the beginning, then no social skills or technology-wise or alike system will foster the share of knowledge. Huysman\& Wit, (2002). Burges (2005) also argues that there is the tendency of institutions to focus mainly on tools, like implementing different collaborative software for knowledge sharing, or on tasks, such as organizational routines and norms and pay less attention to the interactions between people and their characteristics and motivations as knowledge sharing facilitators. Consequently, one of the major reasons why knowledge sharing is still a challenge, the exception rather than the rule Bock, et al., (2005), is that knowledge is embodied in individuals and therefore, they are the ones making choices about sharing their knowledge.

Conceptually, most scholars need to possess humility in order to explore their potentials. Humility is idea is a ripe ingredient and debatable concept. Humble persons possess a self-regulatory capacity that guards against excess arrogance and fosters pro-social tendencies (Jankowski et al., 2013). In understanding humility, it is important for university scholars and practitioners alike because it underlies the choice and capacity to approach one's work (and life) from a larger, interdependent perspective that is productive, relational and sustainable. Humility is generally considered a character strength that is deeply aligned with and uniquely representative of the interdependent nature of today's universities and intelligence of academicians (Frostenson 2016). Humble individuals do not have strong needs to self-enhance or to dominate others (Peterson and Seligman 2004). Humble individuals understand their own strengths and limitations accurately. Humility is often used modesty or is defined as the opposite of arrogance or narcissism; however, the relevant research is unclear.

In light of anticipated challenges and changes that continue to unfold in the 21st century, scholars in public and private institutions have suggested a greater need for organizational members to have the humility to acknowledge areas of ignorance and inexperience and to foster the learning and adaptation that will be required to succeed in an increasingly unpredictable workplace. Biwott, et al., (2019). Woodcock (2008) defined modesty as the quality of being unassuming or otherwise having a moderate estimation of oneself. In displaying modesty, people under-represent their own positive traits, contributions and expectations (Cialdini and de Nicholas 1989). Humble persons hold a balanced perspective that acknowledges both strengths and limitations and does not seek to under or over-represent the self (Morris et al., 2005). Gaps in the literature on the role of humility in universities provide fertile ground for this review. If not adequately examined, questions regarding the crucial role of humility to organizational performance may stymie research progress. This study moves beyond recent studies in the universities domain that review the humility concept (Ou et al. 2014). Specifically, the purpose of the article is threefold:

- To identify employee humility "intelligence unmasked"

- To evaluate the concept of Academic staff knowledge sharing behavior:

- To explore any inherent details of the relationship between Employee humility and knowledge sharing behaviour Thus, this study draws from Self-concept theory ((Jankowski et al. 2013). This paper is organized as follows: first, we clarify self-concept theory, followed by humility construct unmasked. Methodology, results of the study, conclusions and recommendations is covered in subsequent sections. The results of the study are logically organized based on objectives of the study.

\subsection{Theory of Self-Concept}

Self-concept theory is one of the most used theories that help to explain the behavior of employees and employers at work places Blau et al., (1964).it assumes that the theory of Self-Concept postulates that humility is associated with stable self-esteem a valuation of self that is neither overly high nor low, or a grounded sense of self. What might describe how this grounded view of self develops? Baumeister's (1998) theory of self-concept provides some insight into this question. He suggests that through one's experience of oneself, an individual attempts to make sense of his or her world through three prototypical patterns of experiences: reflexive consciousness, interpersonal being, and the executive function. Through the experience of reflexive consciousness, the individual attempts to understand the self in relationship to the world. Through the experience of interpersonal being, he or she attempts to understand oneself in relationship to other people. And through the executive function, the individual attempts to understand oneself through what one does; i.e., one's purpose. Thus, in Baumeister's framework, the individual constructs a self-concept based on one's relationship to the world in which one lives, the relationships one has with others, and the relationship to one's purpose in the world. Viewing humility through the lens of theory of self-concept, there appears to be theoretical support for the suggestion that the humble individual is likely to have a self-concept that involves seeing oneself as a small part of something bigger in the world (as opposed to seeing oneself as the center of one's world). Further, the humble individual is likely to have an appreciation of others and their inherent worth, and a commitment to a purpose that is bigger than oneself.

\subsection{Employee Humility "Intelligence Unmasked"}

Morris, et al., (2005) argues that the relationship between high self-esteem and humility is likely to be contingent on the extent to which one's self-esteem reflects authentic versus defensively high self-esteem. In their view, those with 
defensively high self-esteem can't admit their privately held negative self-views due to their inordinate need for external (social) approval. Biwott, et al., (2019) use the contingencies of self-worth framework as a lens for viewing the construct of humility, there appears to be substantial theoretical support for the suggestion that the humble individual is likely to have a more stable, internally-anchored sense of self-worth that does not vary as a consequence of external circumstances or others' assessments. Further, the humble individual is not likely to de-value others in an effort to elevate his or her selfesteem. It is also unlikely that the individual will attempt to avoid others' feedback in an effort to protect a fragile sense of self. Thus, it could be argued that internalized self-worth may serve as a protective buffer of sorts when the individual is confronted with trying external circumstances or harsh evaluations by others.

Humility is about appreciating something greater than oneself. One might be humbled by the stars on a clear night; by the contemplation of one's deity; or by witnessing a great act of heroism. These particular things might humble servant-leaders, of course, but in addition, servant-leaders tend to be humbled by the cause they serve. For the servantleader, "it's not all about me" it's about serving something greater than me Biwott, et al., (2019). Humility binds leaders and followers together. Servant-leaders do not see themselves as better than those who follow them. They do not act as if they were above their followers. The servant-leader plays the role of primus inter pares first among equals to use Robert K. Greenleaf's term. Great loyalty comes when followers feel the leader "is one of us."

Humility inspires followers to trust leaders. As the saying goes, "humility is not about thinking less of yourself, it's about thinking of yourself less" that is, humility should not be confused with a lack of self-confidence or insecurity. Quite the contrary, self-confidence and self-security are often displayed most authentically through humility. Humility is valuable because self-confident and self-secure leaders tend to inspire great trust in their leadership. Humility is related to sustainable organizational excellence. Jim Collins saw a pattern in the research behind his book, Good to Great: On one hand, a company might show a leap of performance under a "talented but egocentric leader," only to decline in later years. On the other hand, a company with a humble leader was more likely to sustain greatness after that leader departed. In the latter case, it seemed that the humble leader imparted greatness to the company. In the former case, it seemed the egocentric leader did not.

\subsection{Concept of Academic Staff Knowledge Sharing Behavior}

Knowledge sharing behavior refers to a set of individual behaviors involving sharing and/or disseminating one's acquired "work-related knowledge and expertise with other members within" the university (Ghojavand \& Abdali, 2012). Knowledge sharing practice is quite significant for individuals seeking to improve their performance and career as well as for organizations aiming to achieve their success and longevity Biwott, et al., (2019). Knowledge sharing practice is manifested in the social interaction among individuals to exchange information, knowledge, experiences, skills, concepts, thoughts, opinions, insights, ideas (Durmusoglu et al., 2014). Literature, such as Bartol and Srivastava (2002), suggests that Knowledge Sharing Behaviour has four major components by which individuals share their knowledge within an organization, which include, the contribution of knowledge to organizational databases; sharing knowledge in formal interactions within or across teams or work units; thirdly, sharing knowledge in informal interactions among individuals; and fourthly sharing knowledge within communities of practice, which are voluntary forums of employees in an organization.

\subsection{Employee Humility and Knowledge Sharing Behaviour}

Humility is the lack of feeling of superiority, arrogance, and haughtiness of a person towards other people. It is treating all people regardless of who they are, with respect, gentleness, kindness, and forgiveness. Humility has been described from a positive aspect, i.e., with emphasis on strength rather than weakness (Tangney, 2000). Similarly, humility is a virtue that concerns human limits on how to view and handle human limits productively, adaptively, and constructively. Given its focus on limits, no wonder humility makes some uncomfortable. Grenberg, (2005) has been identified as a much-neglected topic in social science (Tangney, 2000). Crossan et al., (2008) make humility in organizations an idea whose time has come. In light of anticipated challenges and changes that continue to unfold in the 21st century, scholars in public and private institutions have suggested a greater need for organizational members to have the humility to acknowledge areas of ignorance and inexperience and to foster the learning and adaptation that will be required to succeed in an increasingly unpredictable workplace Biwott, et al., (2019).

\section{Methodology of the Study}

This study employed an explanatory research design built around testing of the stated objective (Hair et al., 2013). An explanatory research design is a study that seeks to establish a relationship that exists between variables. Its purpose is to identify how one variable affects the other; it seeks to provide an explanation of the causes and effects of one or more variables (Saunders et al., 2007). Sekeran et al., (2013) explains that an explanatory research study is undertaken in order to investigate the cause-effect relationship and describe the characteristics of the variables of interest in a situation by offering a profile to describe relevant aspects of the phenomenon of interest to the researcher from an individual, organizational to industry perspective Biwott, et al., (2019).Thus this study sought to determine the effect of social skills on knowledge sharing behavior and to examine its relationship therefore; it is explanatory research design.

\section{Results and Discussions}

Sections 3.1 and 3.2 of this paper focus on the employee humility in the Universities and underlying effects on knowledge sharing behaviour. 


\subsection{Descriptive Statistics for Humility}

The sixth predictor variable of the study was Humility. The results are presented in Table 1 . The results indicate that universities employees normally find it difficult to keep themselves motivated as indicated by $(M=3.320, S D=1.306)$ The results further shows that most of universities employees are usually able to find humility control on others as indicated by mean $(M=3.750, S D=1.039)$. The results shows that most of the employees on the whole are pleased and humbled with their lives as indicated by the mean $(M=4.000, S D=1.068)$.

Further most employees often would describe themselves as a humble intellectual as shown by the results $(M=3.880, S D$ $=0.937$ ). The results also shows that employees tend to get involved in things they later wish they could get out of as shown by the mean $(M=3.660, S D=1.231)$. Finally, the results shows that employees often pause and think about their feelings as indicated by $(\mathrm{M}=3.820, \mathrm{SD}=1.162)$

Overall mean of $(M=3.754, S D=0.661)$ shows that most university employees portray humility. Further the result shows that the data experienced no skewness and kurtosis problems $(-0.713 \& 0.060)$.

\begin{tabular}{|c|c|c|c|c|}
\hline $\mathbf{n = 3 7 8}$ & Mean & Std. Dev & Skewness & Kurtosis \\
\hline I normally find it difficult to keep myself motivated & 3.320 & 1.306 & -0.368 & -1.002 \\
\hline I'm usually able to find humility control on others & 3.750 & 1.039 & -1.182 & 1.201 \\
\hline On the whole, I'm pleased and humbled with my life. & 4.000 & 1.068 & -1.054 & 0.368 \\
\hline I would describe myself as a humble intellectual & 3.880 & 0.937 & -0.634 & -0.295 \\
\hline I tend to get involved in things I later wish I could get out of. & 3.660 & 1.231 & -0.620 & -0.771 \\
\hline I often pause and think about my feelings. & 3.820 & 1.162 & -0.775 & -0.522 \\
\hline Humility & 3.754 & 0.661 & -0.713 & 0.060 \\
\hline
\end{tabular}

Table 1: Descriptive Statistics for Humility

Source: Research data (2019)

\subsection{Factor Analysis Results for Humility}

The factor analysis results for humility are presented in Table 2. The principal component analysis with Varimax rotation was performed to identify the underlying factors of humility. The results depicted that the high factor loading scores showed that all the items explained humility as all items used to measure humility were all above the minimum recommended value of 0.50 . The he EFA extracted 1 factor with an Eigen value of 2.503 which is above the accepted value of 1 (Yong \& Pearce, 2013) and cumulative extracted variance of $41.722 \%$. Thus, the item was appropriate to explain the variable. Biwott, et al., (2019). Moreover, from the Table 4.19 below, Bartlett's Test of Sphericity produced a significant Chi-Square $\left(\chi^{2}\right)$ of $833.67(\rho<0.05)$ and Kaiser - Meyer - Olkin measure of sampling adequacy was 0.665 above the acceptable value of 0.50 (Field, 2005), showing that it was appropriate to subject data for factor analysis on this variable of humility.

\begin{tabular}{|c|c|c|}
\hline & 1 & 2 \\
\hline On the whole, I'm pleased and humbled with my life. & 0.684 & \\
\hline I would describe myself as a humble intellectual & 0.746 & \\
\hline I tend to get involved in things I later wish I could get out of. & 0.837 & \\
\hline I often pause and think about my feelings. & 0.843 & \\
\hline I normally find it difficult to keep myself motivated & & 0.852 \\
\hline I'm usually able to find humility control on others & & 0.778 \\
\hline \multicolumn{3}{|c|}{ Total Variance Explained: Rotation Sums of Squared Loadings } \\
\hline Initial Eigenvalues & 2.503 & 1.813 \\
\hline$\%$ of Variance & 41.722 & 30.216 \\
\hline Cumulative \% & 41.722 & 71.939 \\
\hline \multicolumn{3}{|l|}{ KMO and Bartlett's Test } \\
\hline Kaiser-Meyer-Olkin Measure of Sampling Adequacy. & & 0.665 \\
\hline \multicolumn{3}{|l|}{ Bartlett's Test of Sphericity } \\
\hline Approx. Chi-Square & & 833.67 \\
\hline Df & & 15 \\
\hline Sig. & & 0.000 \\
\hline
\end{tabular}

Table 2: Humility Rotated Component Matrix Scale Item Factor Loadings

Rotation Method: Varimax with Kaiser Normalization

Source: Research Data (2019)

\subsection{Relationship between Humility and Knowledge Sharing Behaviour}

The objective stated that there is no significant effect of Humility on knowledge sharing behaviour among academic staff in Kenyan universities. However, the findings in Table 2 showed that humility has a positive and significant effect on knowledge sharing behaviour $(\beta 1=0.300, \mathrm{p}<0.05)$. This implies that there is a probability of 0.300 that knowledge sharing behaviour would increase with increase in the humility. Thus, the hypothesis was rejected. More findings in Table 4.28 revealed the effect on the knowledge sharing behaviour is attributed to humility by over 6 times $(t=6.523)$ more compared to the effect attributed to the standard error associated with it. This was supported by Crossan 
et al., (2008) make humility in organizations an idea whose time has come. In light of anticipated challenges and changes that continue to unfold in the 21st century, scholars in public and private institutions have suggested a greater need for organizational members to have the humility to acknowledge areas of ignorance and inexperience and to foster the learning and adaptation that will be required to succeed in an increasingly unpredictable workplace Biwott, et al., (2019).

\section{Conclusion and Implications}

The study also concluded that, it was clear that improving the humility of employees in the university would result in improved employee knowledge sharing behaviour and in general improved organizational performance. As noted, humility enabled employees to recognize a wide range of emotional signals and this enabled them to sense the felt, unspoken, emotions in fellow employees or groups and handled it before it exploded to affect knowledge sharing and performance.

Humility had a positive and significant effect on knowledge sharing behaviour $(\beta 1=0.300, p<0.05)$. The implication is that, good humility enhances knowledge sharing behaviour among universities staff. Most of the respondents agreed or strongly disagreed that humility among employees encourages good relationship which in general enhances employee performance and knowledge sharing among the Universities staff. This was backed up by Crossan et al., (2008) make humility in organizations an idea whose time has come. In light of anticipated challenges and changes that continue to unfold in the 21st century, scholars in public and private institutions have suggested a greater need for organizational members to have the humility to acknowledge areas of ignorance and inexperience and to foster the learning and adaptation that will be required to succeed in an increasingly unpredictable workplace.

\subsection{Implications for Theory}

The theoretical implication for this study is centered on a suggested paradigmatic shift from masked humility approach to self-concept approach "unmasked intelligence". The theoretical implication of the current study is that though self-concept theory is useful in reconciling various interests, humility issues may influence the results due to unmasked intelligence outcomes between humility concept and knowledge sharing behaviour.

\subsection{Implications for Managerial Practice and Policy}

Apparently poor academic staff orientation on humility in Kenya's Universities is intelligence unmasked. However, lack of satisfaction on key humility issues may lead to direct association with negative outcomes of knowledge sharing behavior intelligence. Presumably, employee's knowledge sharing could be as a result of unique humility factors in African universities context. If unmasked, this is unlikely to be sustainable since knowledge and humility dynamics are fast gaining currency in Africa. Further the study could have managerial implications on adoption of strategic humility self-concept referred to as "intelligence unmasked" humility on certain key areas of the universities.

The key to understanding the unmasked intelligence of humility advantages is connected to the three components of humility. First, humble leaders understand their strengths and weaknesses. This knowledge provides leaders with a more accurate view of where they need professional development or what kinds of people, they should partner with to achieve goals. Second, humble leaders are keenly aware of their relationships with others and express empathy and respect for others. Humble leaders aren't simply self-interested. They know they are a part of a community. The leadership advantage of a relationship orientation is that such leaders enter into the emotions of others and are able to regulate their own emotions to be less reactive and more effective in handling others emotions and concerns. Finally, humble leaders practice transcendence, that is, they have a sense of being connected to something bigger than themselves or even their organization. Humble leaders are able to consider multiple perspectives during decision making rather than being blinded by solely the economic or market needs of their firm. Humble leaders can see problems holistically and work constructively with others, even with those who disagree, to generate a larger number of possible solutions.

Effective leaders are often inspiring and effective because they are passionate about their cause and mission. One trait of humble servant leaders is that they are "all in" and that is one thing that demonstrates that the leader is sincere, and passionate. Humble leaders also don't spend time worrying about being lauded for their achievements. Indeed, this is not a motivator for them. In today's cynical, self-promoting world, a leader that seeks recognition is rarely going to be effective. This is something a humble leader already knows and thankfully doesn't crave anyway.

A participatory approach that is conclusive, effective and satisfactory should be developed. Corporate humble model dialogue should form an integral part of this approach. The universities could adopt industry wide codes and standards that will raise the level of compliance to international acceptable knowledge humility practices of the University industry in Kenya. This may cascade down to some other universities that were not even targeted for study. Government policy framework should incorporate a multi-stakeholder approach to policy formulation. Since competitiveness in the universities in particular depends on humility and human aspects, this could be addressed effectively only through incorporating a new approach based on sustainability and competitiveness.

\subsection{Recommendations for Further Study}

The study should be extended to other related industries in other context in Africa and be compared with classified universities. Since the theoretical underpinnings of responsible competitiveness or sustainable competitiveness is still developing, it may be necessary to explore the aspects of the subject using qualitative methods in order to build knowledge and propositions. There is also possibility of applying longitudinal design to the concept of humility and competitiveness. Finally, several unmasked intelligences of humility, found by this study to coexist with otherwise theoretically inconsistent employee knowledge sharing behavior about the universities could be explored further. 


\section{References}

i. $\quad$ Bartol, Kathryn M. \& Srivastava, Abhishek (2002). Encouraging knowledge sharing: the role of organizational reward systems. Journal of Leadership \& Organizational Studies, summer, 9, 64-76

ii. Baumeister, R. F. (1998). The self. In. The handbook of social psychology San Diego, CA, US: Academic Press.

iii. Biwott, G., Limo, P \& Maru, L. (2019). Do self-awareness and self-regulation affect knowledge sharing behaviour? Evidence from Kenyan universities: intelligence unmasked. Journal of Business Management and Economic Research.

iv. Biwott, G., Maru, L., \& Limo, P. (2019). Employee Social Skills as an Antecedent to Knowledge Sharing Behaviour in Kenyan Universities. African Journal of Education, Science and Technology.

v. Blau, P. M. (1964). Exchange and power in social life. New York: John Wiley

vi. Bock G. W., Zmud R. W., Kim Y. G. and Lee J. N. (2005). "Behavioral intention formation in knowledge sharing: Examining the roles of extrinsic motivators, social-psychological forces, and organizational climate", MIS Quarterly, Vol. 29, No. 1, pp. 87-111.

vii. Burges, D., (2005). What motivates employees to transfer knowledge outside their work unit?. Journal of Business Communication, 42(4), pp. 324-348

viii. Cialdini, R.B. and de Nicholas, M.E. (1989). Self-presentation by association. Journal of Personality and Social Psychology, 57, pp. 626-631.

ix. Crossan, M., Vera, D., \& Nanjad, L. (2008). Transcendent leadership: Strategic leadership in dynamic environments. Leadership Quarterly, 19, 569-581.

x. Durmusoglu, S., Jacobs, M., Nayir, D., Khilji, S., \& Wang, X. (2014). The quasi-moderating role of organizational culture in the relationship between rewards and knowledge shared and gained. Journal of Knowledge Management, 18(1), 19-37.

xi. Foss, N. J., Husted, K., \& Michailova, S. (2010). Governing Knowledge Sharing in Organizations: Levels of Analysis, Governance Mechanisms, and Research Directions. Journal of Management Studies, 47(3): $455-482$.

xii. Frostenson, M. (2016). Humility in business: a contextual approach. Journal of Business Ethics, 138, pp. 91102.

xiii. Ghasemi A, Zahediasl S (2012) Normality tests for statistical analysis: a guide for non-statisticians. Int J Endocrinol Metab 10: 486-489.

xiv. Grenberg, J. M. (2005). Kant and the ethics of humility: A story of dependence, corruption, and virtue. Cambridge, MA: Cambridge University Press.

xv. Grieve, Rachel \& Witteveen, Kate \& Tolan, Georgina \& Marrington, Jessica. (2013). Face-to-face or Facebook: Can social connectedness be derived online? Computers in Human Behavior. 29. 604-609.

xvi. Hair J.F., Jr, \& Celsi, Mary \& Money, Arthur \& Samouel, Phillip \& Page, Michael. (2013).The essentials of business research methods: 3rd Ed. 1-494.

xvii. Huysman, M., \& de Wit, D. (2002). Knowledge Sharing in Practice. The Netherlands: Kluwer Academic Publishers.

xviii. Jankowski, P.J., Sandage, S.J. and Hill, P.C. (2013). Differentiation-based models of forgivingness, mental health and social justice commitment: mediator effects for differentiation of self and humility. Journal of Positive Psychology, 8, pp. 412-424.

xix. Kalling, T., \& Styhre, A. (2003). Knowledge sharing in organizations. Sweden: Copenhagen Business School Press

xx. Morris, J.A., Brotheridge, C.M. and Urbanski, J.C. (2005). Bringing humility to leadership: antecedents and consequences of leader humility. Human Relations, 58, pp. 1323-1350.

xxi. Sekaran, U. and Bougie, R. (2013) Research Methods for Business A Skill-Building Approach. 6th Edition, Wiley, New York.

xxii. Seligman et al., (2004). Lift up your heart. Character strengths and virtues: A handbook and classification. New York, NY: McGraw-Hill, p. 146

xxiii. Tangney, J.P. (2000). Humility: theoretical perspectives, empirical findings and directions for future research. Journal of Social and Clinical Psychology, 19, pp. 70-82

xxiv. Further reading

xxv. Ou, A.Y., Tsui, A.S., Kinicki, A.J., Waldman, D.A., Xiao, Z. and Song, L.J. (2014). Humble chief executive officers' connections to top management team integration and middle managers' responses. Administrative Science Quarterly, 59, pp. 34-72.

xxvi. Woodcock, S. (2008). The social dimensions of modesty. Canadian Journal of Philosophy, 38, pp. 1-29. 